\title{
Acetazolamide Therapy in Patients with Heart Failure: A Meta-Analysis
}

\author{
Janewit Wongboonsin ${ }^{1,2}$, Charat Thongprayoon ${ }^{3}$, Tarun Bathini ${ }^{4}$, Patompong Ungprasert ${ }^{5}$, \\ Narothama Reddy Aeddula ${ }^{6}\left(\mathbb{D}\right.$, Michael A. Mao ${ }^{3}[$ and Wisit Cheungpasitporn $7, * \mathbb{1}$ \\ 1 Department of Medicine, University of Minnesota, Minneapolis, MN 55455, USA; jwongboonsin@gmail.com \\ 2 Division of Nephrology, Department of Internal Medicine, Faculty of Medicine, Siriraj Hospital, \\ Mahidol University, Bangkok 10700, Thailand \\ 3 Division of Nephrology and Hypertension, Mayo Clinic, Rochester, MN 55905, USA; \\ charat.thongprayoon@gmail.com (C.T.); mao.michael@mayo.edu (M.A.M.) \\ 4 Department of Internal Medicine, University of Arizona, Tucson, AZ 85721, USA; tarunjacobb@gmail.com \\ 5 Clinical Epidemiology Unit, Department of Research and Development, Faculty of Medicine, \\ Siriraj Hospital, Mahidol University, Bangkok 10700, Thailand; p.ungprasert@gmail.com \\ 6 Division of Nephrology, Department of Medicine, Deaconess Health System, Evansville, IN 47747, USA; \\ dr.anreddy@gmail.com \\ 7 Division of Nephrology, Department of Medicine, University of Mississippi Medical Center, \\ Jackson, MS 39216, USA \\ * Correspondence: wcheungpasitporn@gmail.com
}

Received: 28 January 2019; Accepted: 8 March 2019; Published: 12 March 2019

\begin{abstract}
Background and objectives: Fluid overload and central sleep apnea are highly prevalent in patients with heart failure (HF). We performed this meta-analysis to assess the effects of acetazolamide therapy on acid/base balance and apnea indexes. Methods: A literature search was conducted using EMBASE, MEDLINE, and Cochrane Database from inception through 18 November 2017 to identify studies evaluating the use of acetazolamide in HF. Study results were analyzed using a random effects model. The protocol for this systematic review is registered with PROSPERO (International Prospective Register of Systematic Reviews; no. CRD42017065401). Results: Nine studies (three randomized controlled trials and six cohort studies) with a total of $229 \mathrm{HF}$ patients were enrolled. After acetazolamide treatment, there were significant decreases in serum $\mathrm{pH}$ (mean difference (MD) of -0.04 (95\% CI, -0.06 to -0.02$)$ ), $\mathrm{pCO}_{2}$ (MD of $-2.06 \mathrm{mmHg}$ ( $95 \% \mathrm{CI},-3.60$ to $-0.53 \mathrm{mmHg}$ )), and serum bicarbonate levels (MD of $-6.42 \mathrm{mmol} / \mathrm{L}(95 \% \mathrm{CI}$, -10.05 to $-2.79 \mathrm{mmol} / \mathrm{L})$ ). When compared to a placebo, acetazolamide significantly increased natriuresis (standardized mean difference (SMD) of 0.67 (95\% CI, 0.08 to 1.27)), and decreased the apnea-hypopnea index (AHI) (SMD of $-1.06(95 \% \mathrm{CI},-1.75$ to -0.36$)$ ) and central apnea index (CAI) (SMD of $-1.10(95 \% \mathrm{CI},-1.80$ to -0.40$)$ ). Egger's regression asymmetry tests revealed no publication bias with $p=0.20,0.75$ and 0.59 for analysis of the changes in $\mathrm{pH}, \mathrm{pCO}_{2}$, and serum bicarbonate levels with use of acetazolamide in HF patients. Conclusion: Our study demonstrates significant reduction in serum $\mathrm{pH}$, increase in natriuresis, and improvements in apnea indexes with use of acetazolamide among HF patients.
\end{abstract}

Keywords: acetazolamide; diuretics; heart failure; sleep apnea; meta-analysis

\section{Introduction}

Heart failure affects $1-2 \%$ of the world population with a higher crude prevalence in high-income countries [1]; however, its economic burden has grown globally. Fluid management is one of the therapeutic keystones in assuring symptom and hospital admission control. Despite the ongoing 
development of advanced therapies, heart failure patients are facing new challenges due to a greater prevalence of advanced concurrent chronic kidney disease (CKD) and diuretic resistance [2]. While loop diuretics and thiazide diuretics are the primary diuretic therapy choice, other nephron tubular sites for diuretic blockage have not been commonly utilized and could serve as another avenue for intervention.

Acetazolamide is a carbonic anhydrase inhibitor that blocks proximal tubular absorption of sodium. Acetazolamide was first used in humans as a new diuretic with potential to treat congestive heart failure [3] after it was found to be more potent and safer than sulfanilamide diuretic. Several case studies in the 1950s that utilized acetazolamide in heart failure patients demonstrated successful decongestive profiles [4-6]. Its use had been declining with the discovery of loop diuretics, which are perceived as more potent [7]. However, there were new pieces of evidence showing that the ceiling effect of acetazolamide was due to a compensatory increase of distal tubular $\mathrm{Na}-\mathrm{Cl}$ co-transporter mediated by decreased expression of pendrin, making dual use of acetazolamide and thiazide diuretics a promising therapy for diuretic resistance [8,9]. Recently, Imiela et al. performed a randomized control trial on the effect of acetazolamide on heart failure, showing a positive effect on diuretic augmentation [10]. There are ongoing clinical trials that specifically investigate the effect of acetazolamide on volume overload state; however, the results are still pending. Therefore, a systematic review could provide a comprehensive background and understanding of current evidence in this clinical scenario.

Acetazolamide has also been routinely used in altitude medicine [11] to prevent and treat fluid retention and pulmonary edema by increasing diuresis, improving oxygenation and decreasing periodic breathing patterns [12]. Patients with central sleep apnea (CSA) have demonstrated better control of the apnea-hypopnea index (AHI) when treated with acetazolamide; however, its application in heart failure patients with sleep disorders has not yet been implemented as common practice due to concerns of urinary potassium wasting and the resulting potential arrhythmias [13]. As central sleep disorder is a relatively common comorbidity in heart failure patients, with a reported rate of up to $30-50 \%$ in heart failure patients experiencing reduced left ventricular ejection fraction, acetazolamide could be an additional therapeutic option that would not only help with the volume aspect of heart failure but also the improvement of respiratory indices.

We performed a systematic review and meta-analysis to measure the overall potency of acetazolamide in heart failure patients with a focus on acid/base alterations and alleviation of sleep apnea indices.

\section{Methods}

\subsection{Search Strategy and Literature Review}

The protocol for this systematic review is registered with PROSPERO (International Prospective Register of Systematic Reviews; no. CRD42017065401). A systematic literature search of EMBASE (1988 to 18th November 2017), MEDLINE (1946 to 18th November 2017), and the Cochrane Database of Systematic Reviews (database inception to 18th November 2017) was performed to identify studies evaluating the use of acetazolamide in HF patients. The systematic literature review was performed independently by two investigators (J.W. and C.T.) using the keywords and medical subject heading (MeSH) terms of "acetazolamide" or "diamox", and "heart failure" (provided in online Supplementary Data S1). Additionally, a manual search for conceivably relevant articles using references of the included articles was also performed. This study was conducted in accordance with the STROBE (Strengthening the Reporting of Observational Studies in Epidemiology) [14] and the PRISMA (Preferred Reporting Items for Systematic Reviews and Meta-Analysis) statements [15] as described in online Supplementary Data S1. 


\subsection{Selection Criteria}

Eligible studies consisted of clinical trials or observational studies (cohort, case-control, or cross-sectional studies) that assessed the effects of acetazolamide therapy on 1) acid/base balance and 2) apnea indexes. The studies were included only if they provided data allowing for the calculation of mean differences (MDs), standardized mean differences (SMDs), relative risks, or hazard ratios with $95 \%$ confidence intervals (CI). Retrieved articles were individually reviewed for eligibility by the two investigators (J.W. and C.T.). Discrepancies were resolved by mutual consensus. The quality of each included study was quantified via the Cochrane risk of bias tool [16]. The Newcastle-Ottawa quality assessment scale was utilized to appraise the quality of study for observational studies [17].

\subsection{Data Abstraction}

A structured data collecting form was utilized to derive the following information from each study: name of the first author, title, year of the study, publication year, country where the study was conducted, demographic and characteristic data of heart failure patients, methods used to identify heart failure, acetazolamide regimen and dosages, data on fluid and electrolytes, apnea indexes, and adjusted effect estimates with $95 \%$ CI.

\subsection{Statistical Analysis}

Comprehensive Meta-Analysis software (version 3.3.070; Biostat Inc, Englewood, New Jersey, USA) was used for the analyses. Adjusted point estimates from each included study were consolidated by the generic inverse variance approach of DerSimonian and Laird, which designated the weight of each included study based on its variance [18]. Given the likelihood of between-study variance, we used a random-effect model rather than a fixed-effect model. Cochran's $Q$ test with $\mathrm{I}^{2}$ statistics were applied to assess the between-study heterogeneity. An $\mathrm{I}^{2}$ value of $0 \%$ to $25 \%$ indicates insignificant heterogeneity, $26 \%$ to $50 \%$ low heterogeneity, $51 \%$ to $75 \%$ moderate heterogeneity and $76 \%$ to $100 \%$ high heterogeneity $[16,19]$. The Egger test was used to assess the presence of publication bias [20].

\section{Results}

A total of 614 potentially eligible articles were identified using our search strategy. After excluding 571 articles that did not fulfill inclusion criteria on the basis of type of article, study design, population, and outcome of interest, 43 articles were left for full-length review (Supplementary Data S1). Thirty-four of the final 43 articles were additionally excluded from full-length review, as shown in Figure 1. Thus, the final analysis included nine articles consisting of three randomized controlled trials and six cohort studies with a total of $229 \mathrm{HF}$ patients. The literature retrieval, review, and selection process are demonstrated in Figure 1. 


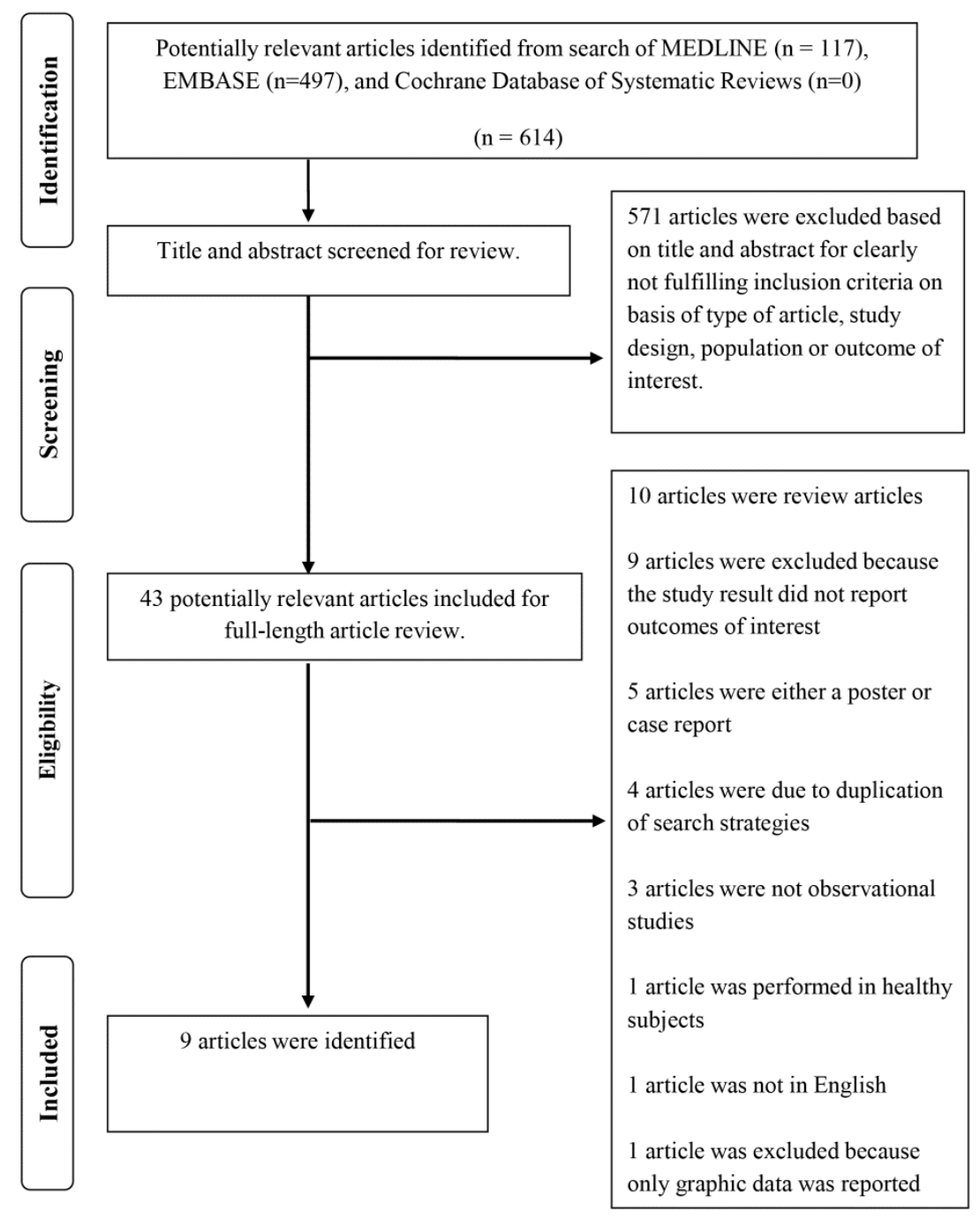

Figure 1. Outline of our search methodology.

The characteristics and quality assessment of the included studies are presented in Tables 1 and 2. Table 1 describes the main characteristics of experimental studies that utilized acetazolamide as a treatment agent in patients with heart failure. The two studies from Javaheri et al. [21,22] used acetazolamide as an experimental drug and monitored several sleep disorder parameters. Both studies shared similar methodologies. The third study by Imiela et al. [10] was one of the first randomized controlled trials that was dedicated to heart failure outcomes including urine output and clinical measurements. Table 2 summarizes important descriptions of observational studies that focused on acetazolamide in various settings of heart failure patients. It is of note that three out of six were performed prior to the era of evidence-based medicine; therefore, case definition and measured parameters may deviate from the other studies. Amongst the other three studies that were performed more recently, all share similar quality of case selection and ascertainment of exposure (diuretics). 
Table 1. Main characteristics of the RCTs included in the meta-analysis of acetazolamide therapy in heart failure patients.

\begin{tabular}{|c|c|c|c|c|}
\hline & $\begin{array}{l}\text { Study (Author, } \\
\text { Year) }\end{array}$ & Javaheri, 2006 [21] & Javaheri, 2014 [22] & Imiela, 2017 [10] \\
\hline \multirow{6}{*}{ Method } & Study design & $\begin{array}{c}\text { RCT, double-blind cross-over placebo } \\
\text { and acetazolamide }\end{array}$ & $\begin{array}{l}\text { RCT, double-blind cross-over placebo } \\
\text { and acetazolamide }\end{array}$ & RCT, single-center, unblinded \\
\hline & Total number & 12 & 6 & 20 \\
\hline & Patient sample & Stable systolic heart failure & Stable systolic heart failure & $\begin{array}{l}\text { Patient hospitalized with chronic heart } \\
\text { failure exacerbation }\end{array}$ \\
\hline & CHF definition & $\begin{array}{c}\text { Systolic HF }(\mathrm{EF}<35 \%) \text { with } \\
\text { Cheyne-Stokes breathing and AHI }> \\
15 / \mathrm{h}\end{array}$ & $\begin{array}{l}\text { Systolic heart failure and CSA (AHI > } \\
\qquad 15 / \mathrm{h})\end{array}$ & $\mathrm{EF}<50 \%$, signs of volume overload \\
\hline & $\begin{array}{l}\text { Acetazolamide } \\
\text { dosing }\end{array}$ & $\begin{array}{l}\text { Acetazolamide } 3.5-4 \mathrm{mg} / \mathrm{kg}+\mathrm{KCL} \\
60 \mathrm{meq}\end{array}$ & $\begin{array}{l}\text { Acetazolamide } 3.5-4 \mathrm{mg} / \mathrm{kg}+\mathrm{KCL} \\
60 \mathrm{meq}\end{array}$ & $\begin{array}{l}\text { Once daily (dose-adjusted to body weight } \\
\text { range from } 250 \mathrm{mg} \text { to } 500 \mathrm{mg} \text { ) as add-on } \\
\text { diuretics to furosemide }\end{array}$ \\
\hline & Description & $\begin{array}{l}\text { RCT about acetazolmide but } \\
\text { designed for sleep disorder }\end{array}$ & $\begin{array}{l}\text { RCT about acetazolmide but } \\
\text { designed for sleep disorder }\end{array}$ & RCT dedicated to acetazolamide \\
\hline \multirow{6}{*}{$\begin{array}{l}\text { Cochrane risk of } \\
\text { bias }\end{array}$} & Selection & Low & Low & Low \\
\hline & Performance & Low & Low & High \\
\hline & Detection & Low & Low & High \\
\hline & Attrition & Low & Low & Low \\
\hline & Reporting & Low & Low & Low \\
\hline & Other & Low & Low & Low \\
\hline
\end{tabular}

Abbreviations: RCT, randomized controlled trial; $\mathrm{CHF}$, congestive heart failure; EF, ejection fraction; $\mathrm{AHI}$, apnea-hypopnea index; $\mathrm{CSA}$, central sleep apnea; KCL, potassium chloride. 
Table 2. Main characteristics of cohort studies included in meta-analysis of acetazolamide therapy in heart failure patients.

\begin{tabular}{|c|c|c|c|c|c|c|c|}
\hline & Study (Author, Year) & Schwartz, 1955 [23] & Mauck, 1957 [24] & Khan, 1980 [25] & Fontana, 2011 [26] & Apostolo, 2014 [27] & Verbrugge, 2015 [28] \\
\hline \multirow{6}{*}{ Method } & Study design & Cohort, time series & Cohort, time series & Cohort, time series & Cohort & Cohort & Cohort \\
\hline & Total number & 17 & 14 & 74 & 12 & 20 & 54 \\
\hline & Patient sample & $\begin{array}{l}\text { Severe CHF with cor } \\
\text { pulmonale }\end{array}$ & Stable CHF & $\begin{array}{c}\text { Hospitalized } \\
\text { decompensated CHF }\end{array}$ & $\begin{array}{l}\text { CHF with periodic } \\
\text { breathing }\end{array}$ & $\begin{array}{l}\text { CHF with periodic } \\
\text { breathing }\end{array}$ & $\begin{array}{l}\text { Hospitalized decompensated } \\
\text { CHF }\end{array}$ \\
\hline & CHF definition & $\begin{array}{c}\text { Clinical diagnosis with } \\
\text { severe pulmonary disease, } \\
\text { with ECG or Xray change } \\
\text { of right heart enlargement } \\
\text { or strain } \\
\end{array}$ & $\begin{array}{l}\text { Fully digitalized ambulatory } \\
\text { CHF on } 1 \text { gm diet, mostly } \\
\text { edema free. Wash out from } \\
\text { other diuretics for two weeks }\end{array}$ & $\begin{array}{c}\text { Patients diagnosed with } \\
\text { CHF that failed treatment } \\
\text { with furosemide, } \\
\text { spironolactone and salt } \\
\text { restriction } \\
\end{array}$ & $\mathrm{EF}<50 \%$, with $\mathrm{AHI}>15$ & $\begin{array}{l}\mathrm{EF}<40 \% \text {, with periodic } \\
\text { breathing during exercise }\end{array}$ & $\begin{array}{l}\text { At least three signs of volume } \\
\text { overload, } \mathrm{EF}<45 \%\end{array}$ \\
\hline & $\begin{array}{l}\text { Acetazolamide } \\
\text { dosing }\end{array}$ & $1-1.5$ gm over $24 \mathrm{~h}$ & $250 \mathrm{mg}$ qday & $\begin{array}{c}250 \mathrm{mg} \text { qid ( } 1 \mathrm{~g} \text { per day), } \\
\text { used as a replacement of } \\
\text { furosemide }\end{array}$ & $250 \mathrm{mg}$ po bid for 4 days & $\begin{array}{l}500 \mathrm{mg} \mathrm{IV} \text { and prolonged } 2 \\
\text { gm over } 24 \mathrm{~h}\end{array}$ & $250 \mathrm{mg}$ qday \\
\hline & Description & $\begin{array}{l}\text { Using acetazolamide to } \\
\text { treat patient with cor } \\
\text { pulmonale and } \\
\text { respiratory acidosis }\end{array}$ & $\begin{array}{l}\text { Studying effect of } \\
\text { acetazolamide in ambulatory } \\
\text { CHF, aiming at electrolyte } \\
\text { values during therapy }\end{array}$ & $\begin{array}{l}\text { Using acetazolamide } \\
\text { instead of furosemide for } \\
\text { diuresis }\end{array}$ & $\begin{array}{c}\text { Measure breathing } \\
\text { parameters with } \mathrm{ABG} \\
\text { analysis before and after } \\
\text { acetazolamide treatment }\end{array}$ & $\begin{array}{c}\text { Measured respiratory } \\
\text { pattern before and after } \\
\text { acetazolamide treatment }\end{array}$ & $\begin{array}{l}\text { Cohort finding predictor of } \\
\text { natriuresis }\end{array}$ \\
\hline \multirow{4}{*}{$\begin{array}{c}\text { Quality } \\
\text { assessment } \\
\text { (Newcastle- } \\
\text { Ottawa scale) }\end{array}$} & Selection & 2 & 2 & $\begin{array}{c}2 \\
\text { - Independent validation } \\
\text { - Obvious series of cases }\end{array}$ & $\begin{array}{c}3 \\
\text { - Using cohort of CHF } \\
\text { - Non-exposed cohort is self } \\
\text { prior to acetazolamide } \\
\text { - Secure record }\end{array}$ & $\begin{array}{c}3 \\
\text { - Using cohort of CHF } \\
\text { - Non-exposed cohort is self } \\
\text { prior to acetazolamide } \\
\text { - secure record }\end{array}$ & $\begin{array}{c}3 \\
\text { - True representation of CHF } \\
\text { - Same community of control } \\
\text { - Secure record }\end{array}$ \\
\hline & Comparability & 1 & 1 & $\begin{array}{c}1 \\
\text { - Study controls by using } \\
\text { prior-self prior to treatment } \\
\text { with acetazolamide }\end{array}$ & $\begin{array}{c}1 \\
\text { - Study controls by using } \\
\text { prior-self prior to treatment } \\
\text { with acetazolamide }\end{array}$ & $\begin{array}{c}1 \\
\text { - Study controls by using } \\
\text { prior-self prior to treatment } \\
\text { with acetazolamide }\end{array}$ & $\begin{array}{c}2 \\
\text { - Using multivariate analysis } \\
\text { and still showed acetazolamide } \\
\text { as important factor }\end{array}$ \\
\hline & Outcome & 1 & 1 & $\begin{array}{c}1 \\
\text {-Secure record (hospital) }\end{array}$ & NA & NA & NA \\
\hline & Exposure & NA & NA & NA & $\begin{array}{c}2 \\
\text { - Record linkage } \\
\text { - Long follow up }\end{array}$ & $\begin{array}{c}2 \\
\text { - Record linkage } \\
\text { - Long follow up }\end{array}$ & $\begin{array}{c}3 \\
\text {-Record linkage } \\
\text { - Long follow up } \\
\text { - Complete follow up of all } \\
\text { subjects }\end{array}$ \\
\hline
\end{tabular}

Abbreviations: CHF, congestive heart failure; EF, ejection fraction; AHI, apnea-hypopnea index; ECG, electrocardiogram; IV, intravenous; ABG, arterial blood gas; NA, not applicable. 


\subsection{Effects of Acetazolamide on Acid/Base Balance in HF Patients}

After acetazolamide treatment, there were significant decreases in serum $\mathrm{pH}$ (mean difference (MD) of -0.04 (95\% CI, -0.06 to -0.02$), \mathrm{I}^{2}=65 \%$, Figure $2 \mathrm{~A}$ ), $\mathrm{pCO}_{2}$ (MD of $-2.06 \mathrm{mmHg}(95 \% \mathrm{CI}$, -3.60 to $-0.53 \mathrm{mmHg}$ ), $\mathrm{I}^{2}=0 \%$, Figure $2 \mathrm{~B}$ ) and serum bicarbonate levels (MD of $-6.42 \mathrm{mmol} / \mathrm{L}$ $(95 \% \mathrm{CI},-10.05$ to $-2.79 \mathrm{mmol} / \mathrm{L}), \mathrm{I}^{2}=95 \%$, Figure $\left.2 \mathrm{C}\right)$. This finding confirmed the expected effects of acetazolamide use in our population of interest. The changes of $\mathrm{pCO}_{2}$ appeared to be less robust than serum bicarbonate level as reflected by a wider confidence interval in each study. This may be due to variation in the time of blood specimen collection, allowing more variation in the respiratory compensation in response to induced metabolic acidosis. When compared to a placebo, acetazolamide significantly increased natriuresis (standardized mean difference (SMD) of 0.67 (95\% CI, 0.08 to 1.27)), $\mathrm{I}^{2}=0 \%$, Figure 3).

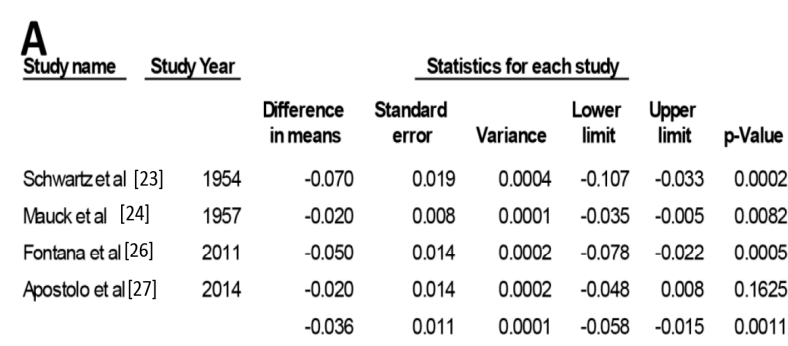

B

\section{$c$}

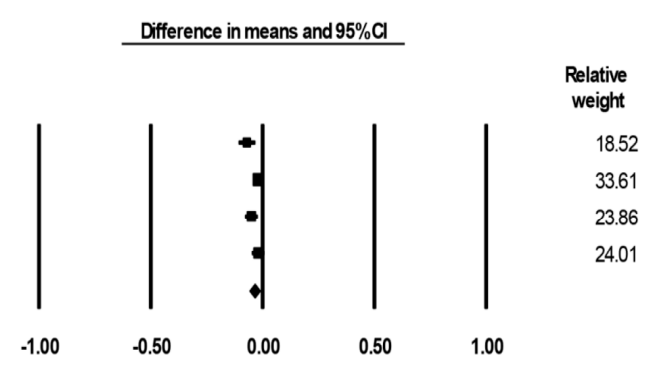

Lower $\mathrm{pH} \quad$ Higher $\mathrm{pH}$

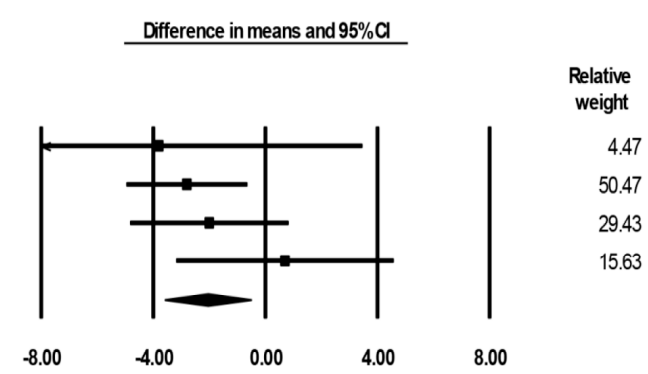

Lower pCO2 Higher pCO2

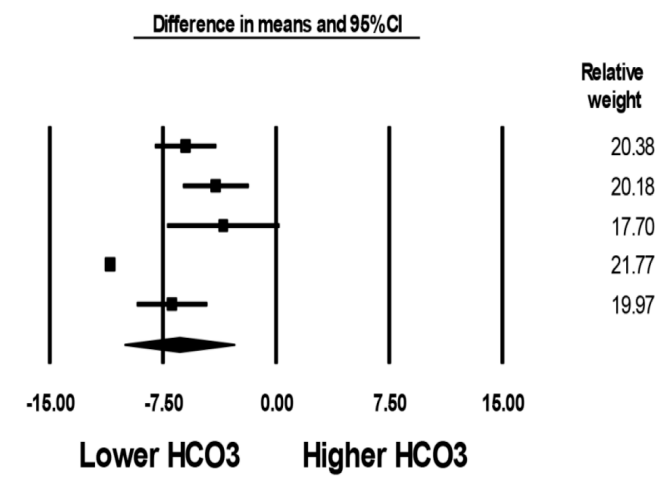

Figure 2. Forest plots of the included studies assessing the effects of acetazolamide on $(\mathbf{A}) \mathrm{pH} ;(\mathbf{B}) \mathrm{pCO}_{2}$; and $(\mathrm{C})$ bicarbonate. A diamond data marker represents the overall rate from each included study (square data marker) and 95\% confidence interval (CI). 


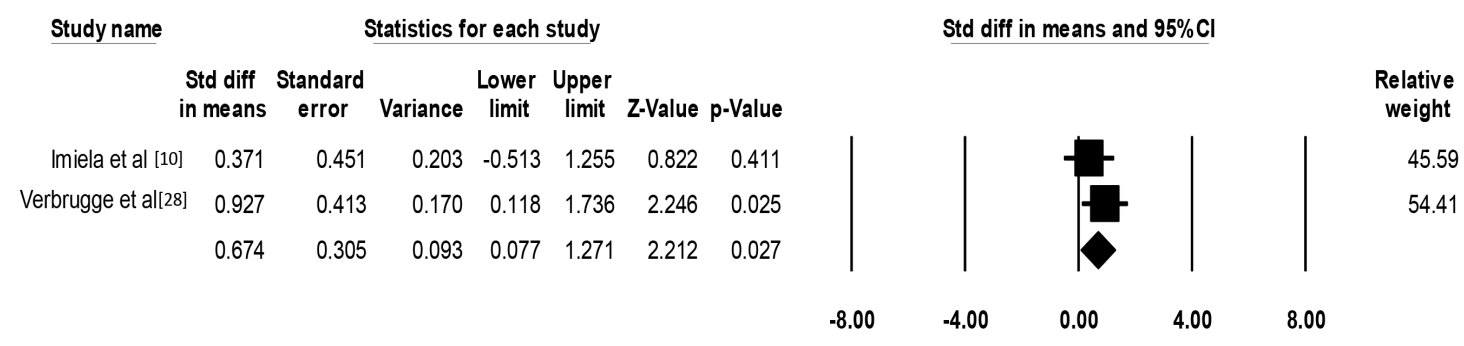

Lower Natriuresis Higher Natriuresis

Figure 3. Forest plot of the included studies assessing effects of acetazolamide on natriuresis, when compared to control. A diamond data marker represents the overall rate from each included study (square data marker) and 95\% CI.

\subsection{Effects of Acetazolamide on Apnea Indexes}

When compared to a placebo, acetazolamide treatment significantly reduced the apnea-hypopnea index (AHI) (SMD of $-1.06,(95 \% \mathrm{CI},-1.75$ to -0.36$), \mathrm{I}^{2}=0 \%$, Figure $\left.4 \mathrm{~A}\right)$ and central apnea index (CAI) (SMD of $-1.10,(95 \% \mathrm{CI},-1.80$ to -0.40$)), \mathrm{I}^{2}=0 \%$ Figure $\left.4 \mathrm{~B}\right)$, respectively. It is important to note that both of the studies included in this analysis came from the same investigator with a very similar study protocol used in each study. As measurement of sleep parameters required an elaborate setting to be quantified, other studies did not contain the data required to be included in the meta-analysis.

A

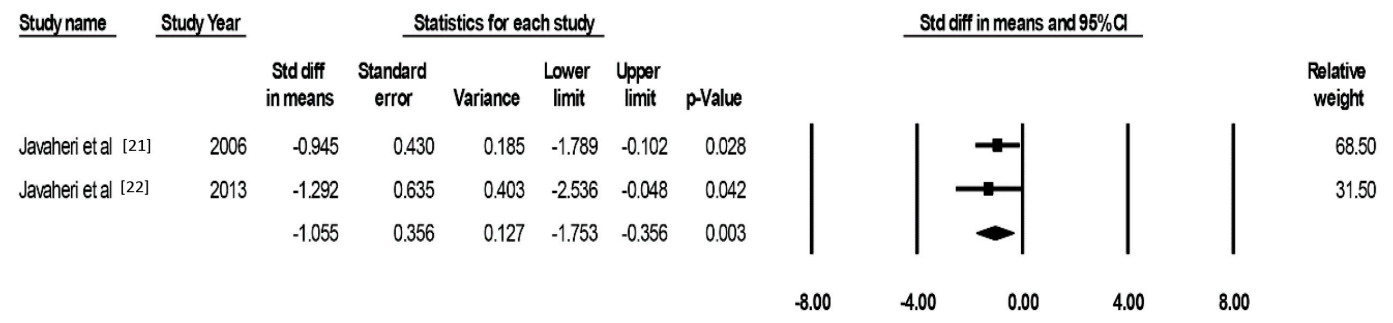

B

\section{Lower AHI Higher AHI}

$\underline{\text { Studyname }}$ Study Year
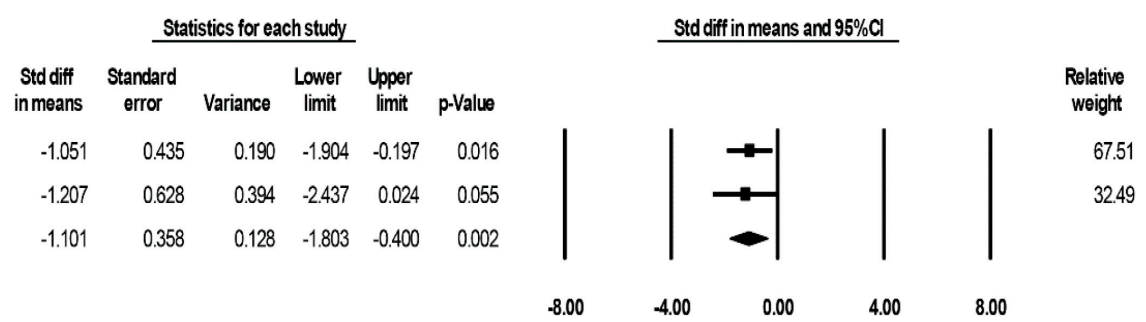

\section{Lower CAl Higher CAI}

Figure 4. Forest plots of the included studies evaluating effects of acetazolamide on (A) apnea-hypopnea index (AHI); and (B) central apnea index (CAI). A diamond data marker represents the overall rate from each included study (square data marker) and 95\% CI. 


\subsection{Sensitivity Analysis}

Sensitivity analysis was performed by excluding one study at a time to investigate the effect of each study on the pooled MD and SMD for each outcome assessed. The pooled effect estimate from the sensitivity analysis remained essentially unchanged.

\subsection{Evaluation for Publication Bias}

We found no publication bias as assessed by the Egger's regression asymmetry test with $p=0.20$, 0.75 and 0.59 for analysis of the changes of serum $\mathrm{pH}, \mathrm{pCO}_{2}$, and serum bicarbonate levels with use of acetazolamide in HF patients, respectively. Since a limited number of included studies evaluated the changes of $\mathrm{AHI}$ and $\mathrm{CAI}$, the power of the test is too low to evaluate the publication bias.

\section{Discussion}

In this meta-analysis, we consolidated the effects of using acetazolamide in populations of heart failure patients. By inducing bicarbonaturia at the level of the proximal tubules, acetazolamide led to a modest decrease in serum bicarbonate (MD of $6.42 \mathrm{mmol}$ ) without a considerable disruption of $\mathrm{pCO}_{2}$ and $\mathrm{pH}$ in this patient population. This suggests that an acetazolamide-induced metabolic acidosis could assist respiratory compensation even in patients with heart failure. There is a reasonable need for caution towards medications that can cause an abrupt change in $\mathrm{pH}$ due to their potential to cause an arrhythmogenic state. Our study, however, showed that acetazolamide use in heart failure only caused minor changes in serum $\mathrm{pH}$ (MD of 0.04), making it a reasonable agent to use in patients who have developed contraction alkalosis from diuresis. In addition, acetazolamide increased natriuresis compared to a placebo, thus supporting prior evidence that showed its use as an adjunct to other diuretics [8-10]. One important note for the pharmacodynamic profile of acetazolamide was the development of tolerance after consecutive days of daily administration [29], which resulted in decreased natriuresis and potassium excretion after $48-72 \mathrm{~h}$. The authors suggested limiting acetazolamide use to no more than three to four days a week or for less than two consecutive days at a time in order to sustain its desired diuretic properties. The mechanism of this phenomenon was unclear and it was unknown whether the effect of acid-base changes may also be affected, suggesting a topic for further experimental research.

Acetazolamide was also shown to improve apnea-hypopnea index and central apnea index in our study. This finding expanded the potential use of acetazolamide in heart failure patients, as sleep apnea is a common comorbidity that is often exacerbated with heart failure decompensation [30]. While controversy existed around the risk or benefit of adaptive servo-ventilation (ASV) use in the heart failure population, continuous positive airway pressure (CPAP) is well accepted as a modality of treatment for obstructive sleep apnea (OSA) in the heart failure population. As compliance with CPAP use remains a substantial barrier to effective treatment of sleep apnea, acetazolamide could potentially serve as an alternative therapeutic modality for this patient population. The mechanism of acetazolamide effect on sleep indices is still unclear. Prior studies have found evidence that acetazolamide paradoxically improved apnea indices despite augmenting hypercapnic ventilatory response, (HCVR) which was thought to be the main pathophysiology of central sleep apnea [22]. Authors have proposed other mechanisms including changes in $\mathrm{O} 2$ and $\mathrm{CO} 2$ chemoreceptor sensitivity as the possible explanation of how acetazolamide led to more favorable apnea indices. It is important to note that in two of the studies that we analyzed, the reduction of AHI was not associated with increased diuresis or an improved cardiac status, suggesting that the effect of acetazolamide in optimizing sleep indices may be independent of the patient's volume status. Future studies exploring the effect of acetazolamide on sleep indices after diuresis has achieved the desired volume status in heart failure patients, and whether the independent beneficial effect persists, will be important. When compared to the non-heart failure central sleep apnea patients, several studies addressed the effect of acetazolamide on CSA and OSA. There was a general trend of acetazolamide improving the CSA sleep parameter and 
sleep-related symptoms, but there conflicting evidence on the effect of OSA sleep parameter. A recent publication by Aurora et al. [31] proposed acetazolamide as an option of CSA for both the heart failure and the non-heart failure patient but acknowledged the potential side effect of the medication. Given the complexity of non-heart failure CSA patients with persistent of $\mathrm{CO}_{2}$ receptor reset [32], ongoing research exploring the impact of acetazolamide in a CHF patient may benefit from additional outcome adjudication after acetazolamide therapy was interrupted.

Potential deleterious effects of acetazolamide include metabolic acidosis, which could transiently increase the sympathetic response of heart failure [21]. It is also possible that hyperventilation as a result of acetazolamide use could lead to increased fatigability of respiratory muscles during the treatment period. Several early studies of acetazolamide reported side effects such as nausea, vomiting, paresthesia, dizziness, and muscle cramps. These symptoms were attributed to electrolyte and acid-base shifts that occurred either from diuresis or were a direct effect of the carbonic anhydrase inhibition on nerve cells [33]. Potassium monitoring and appropriate supplementation will be critical in the effective use of acetazolamide, as reflected in multiple prior studies that included potassium supplementation in the study protocol. In the study from Javaheri 2006 which utilized a slightly higher dose of acetazolamide, one participant reported shortness of breath during the study. The author proposed that the effect was due to the dosage of the medication being higher than what would be used in clinical practice. None of the patients in the study reported cases of paresthesia.

There are several limitations to this meta-analysis. First, the quality of the observational studies was limited as many were performed before the era of modern evidence-based medicine. However, the three selected studies described their protocol meticulously, and by further utilizing the same patients for both the control and exposure population, it resembled a time series methodology. Second, the three cohort studies included were very well-designed studies but were not primarily looking at the effects of acetazolamide on the outcome of our interest; this would introduce potential bias by analyzing previous reported secondary data. On the other hand, the data from the three randomized control trials were of high quality given its sole use of acetazolamide as the main intervention. Only one study did not provide blinding for acetazolamide use, which likely could have led to detection bias in the subjective outcome (dyspnea scale) of the study. However, our pooled data of urinary sodium excretion should be minimally affected. In addition, we performed an additional search of the literature to cover recently published articles up to the time of publication. We identified seven other items [34-40], two of which would qualify for our screening criteria. However, both of the articles did not contain our outcome of interest even though part of the studies involved the usage of acetazolamide. Thus, future large-scale clinical trials are required to confirm these effects of acetazolamide therapy on acid/base balance and apnea indexes.

In summary, our systematic review and meta-analysis suggest that acetazolamide may have a potential beneficial effect in select heart failure patients by reducing serum bicarbonate level and augmenting natriuresis with only slight changes in serum $\mathrm{pH}$ and $\mathrm{pCO}_{2}$. Acetazolamide also helped to reduce sleep apnea indices, expanding its potential use for sleep apnea in the heart failure population. Further studies to explore the mechanism, safety, and beneficial effects of acetazolamide when used in conjunction with other diuretics would be an important next step prior to its widespread adoption in the clinician's armamentarium.

Supplementary Materials: The following are available online at http:/ /www.mdpi.com/2077-0383/8/3/349/s1, Online Supplementary Data S1: search terms for systematic review, list of 43 candidates article reviewed data 1.

Author Contributions: Conceptualization, J.W., C.T., W.C.; data curation, J.W., C.T., M.A.M., W.C.; formal analysis, C.T., W.C.; funding acquisition, T.B. and N.R.A.; investigation, J.W., C.T., P.U., T.B., W.C.; methodology, J.W., C.T., W.C.; project administration, P.U., M.A.M., N.R.A.; resources, T.B., M.A.M.; software, T.B., W.C.; supervision, M.A.M. and W.C.; validation, J.W., C.T. and W.C.; writing-original draft, J.W.; writing-review and editing, J.W., C.T., T.B., P.U., N.R.A., M.A.M., W.C.

Conflicts of Interest: The authors declare no conflict of interest. 


\section{References}

1. Cook, C.; Cole, G.; Asaria, P.; Jabbour, R.; Francis, D.P. The annual global economic burden of heart failure. Int. J. Cardiol. 2014, 171, 368-376. [CrossRef] [PubMed]

2. Bowman, B.N.; Nawarskas, J.J.; Anderson, J.R. Treating Diuretic Resistance: An Overview. Cardiol. Rev. 2016, 24, 256-260. [CrossRef] [PubMed]

3. Friedberg, C.K.; Taymor, R.; Minor, J.B.; Halpern, M. The use of diamox, a carbonic anhydrase inhibitor, as an oral diuretic in patients with congestive heart failure. N. Engl. J. Med. 1953, 248, 883-889. [CrossRef] [PubMed]

4. Herrmann, G.R.; Baxter, M.R.; Hejtmancik, M.R.; Moran, A.R. Diamox: New oral nonmercurial, nontoxic diuretic for the treatment of congestive heart failure. Tex. State J. Med. 1954, 50, 209-213. [PubMed]

5. Belsky, H. Use of a new oral diuretic, diamox, in congestive heart failure. N. Engl. J. Med. 1953, 249, $140-143$. [CrossRef] [PubMed]

6. Suarez, R.M., Sr.; Suarez, R.M., Jr.; Buso, R.; Sabater, J. Diamox; a new non-mercurial diuretic for oral administration; clinical observations on the treatment of edema due to cardiac failure. Bol. Asoc. Med. P. R. 1953, 45, 381-386.

7. Ellison, D.H. The physiologic basis of diuretic synergism: Its role in treating diuretic resistance. Ann. Intern. Med. 1991, 114, 886-894. [CrossRef]

8. Fallahzadeh, M.A.; Dormanesh, B.; Fallahzadeh, M.K.; Roozbeh, J.; Fallahzadeh, M.H.; Sagheb, M.M. Acetazolamide and Hydrochlorothiazide Followed by Furosemide Versus Furosemide and Hydrochlorothiazide Followed by Furosemide for the Treatment of Adults With Nephrotic Edema: A Randomized Trial. Am. J. Kidney Dis. Off. J. Natl. Kidney Found. 2017, 69, 420-427. [CrossRef]

9. Zahedi, K.; Barone, S.; Xu, J.; Soleimani, M. Potentiation of the effect of thiazide derivatives by carbonic anhydrase inhibitors: Molecular mechanisms and potential clinical implications. PLoS ONE 2013, 8, e79327. [CrossRef]

10. Imiela, T.; Budaj, A. Acetazolamide as Add-on Diuretic Therapy in Exacerbations of Chronic Heart Failure: A Pilot Study. Clin. Drug Investig. 2017, 37, 1175-1181. [CrossRef]

11. Ritchie, N.D.; Baggott, A.V.; Andrew Todd, W.T. Acetazolamide for the prevention of acute mountain sickness-A systematic review and meta-analysis. J. Travel Med. 2012, 19, 298-307. [CrossRef] [PubMed]

12. Liu, X.; Sii, F.; Horsburgh, J.; Shah, P. Anuric acute kidney injury due to low dose oral acetazolamide with hypercrystalluria. Clin. Exp. Ophthalmol. 2017, 45, 927-929. [CrossRef]

13. Bekfani, T.; Abraham, W.T. Current and future developments in the field of central sleep apnoea. Europace 2016, 18, 1123-1134. [CrossRef]

14. Von Elm, E.; Altman, D.G.; Egger, M.; Pocock, S.J.; Gotzsche, P.C.; Vandenbroucke, J.P. The Strengthening the Reporting of Observational Studies in Epidemiology (STROBE) statement: Guidelines for reporting observational studies. PLoS Med. 2007, 4, e296. [CrossRef] [PubMed]

15. Moher, D.; Liberati, A.; Tetzlaff, J.; Altman, D.G. Preferred reporting items for systematic reviews and meta-analyses: The PRISMA statement. PLoS Med. 2009, 6, e1000097. [CrossRef] [PubMed]

16. Higgins, J.P.; Altman, D.G.; Gotzsche, P.C.; Juni, P.; Moher, D.; Oxman, A.D.; Savović, J.; Schulz, K.F.; Weeks, L.; Sterne, J.A.C. The Cochrane Collaboration's tool for assessing risk of bias in randomised trials. BMJ 2011, 343, d5928. [CrossRef] [PubMed]

17. Stang, A. Critical evaluation of the Newcastle-Ottawa scale for the assessment of the quality of nonrandomized studies in meta-analyses. Eur. J. Epidemiol. 2010, 25, 603-605. [CrossRef] [PubMed]

18. DerSimonian, R.; Laird, N. Meta-analysis in clinical trials. Control. Clin. Trials 1986, 7, 177-188. [CrossRef]

19. Higgins, J.P.; Thompson, S.G.; Deeks, J.J.; Altman, D.G. Measuring inconsistency in meta-analyses. BMJ 2003, 327, 557-560. [CrossRef] [PubMed]

20. Easterbrook, P.J.; Berlin, J.A.; Gopalan, R.; Matthews, D.R. Publication bias in clinical research. Lancet 1991, 337, 867-872. [CrossRef]

21. Javaheri, S. Acetazolamide improves central sleep apnea in heart failure: A double-blind, prospective study. Am. J. Respir. Crit. Care Med. 2006, 173, 234-237. [CrossRef] [PubMed]

22. Javaheri, S.; Sands, S.A.; Edwards, B.A. Acetazolamide attenuates Hunter-Cheyne-Stokes breathing but augments the hypercapnic ventilatory response in patients with heart failure. Ann. Am. Thorac. Soc. 2014, 11, 80-86. [CrossRef] [PubMed] 
23. Schwartz, W.B.; Relman, A.S.; Leaf, A. Oral administration of a potent carbonic anhydrase inhibitor (diamox). III. Its use as a diuretic in patients with severe congestive heart failure due to cor pulmonale. Ann. Intern. Med. 1955, 42, 79-89. [PubMed]

24. Langford, H.G.; Mauck, H.P. Effect of acetazoleamide (diamox) on the electrolyte patterns of ambulatory patients with mild congestive failure. Am. J. Med. Sci. 1957, 233, 176-181. [PubMed]

25. Khan, M.I. Treatment of refractory congestive heart failure and normokalemic hypochloremic alkalosis with acetazolamide and spironolactone. Can. Med. Assoc. J. 1980, 123, 883-887. [PubMed]

26. Fontana, M.; Emdin, M.; Giannoni, A.; Iudice, G.; Baruah, R.; Passino, C. Effect of acetazolamide on chemosensitivity, Cheyne-Stokes respiration, and response to effort in patients with heart failure. Am. J. Cardiol. 2011, 107, 1675-1680. [CrossRef] [PubMed]

27. Apostolo, A.; Agostoni, P.; Contini, M.; Antonioli, L.; Swenson, E.R. Acetazolamide and inhaled carbon dioxide reduce periodic breathing during exercise in patients with chronic heart failure. J. Card. Fail. 2014, 20, 278-288. [CrossRef]

28. Verbrugge, F.H.; Dupont, M.; Bertrand, P.B.; Nijst, P.; Penders, J.; Dens, J.; Verhaert, D.; Vandervoort, P.; Tang, W.H.W.; Mullens, W. Determinants and impact of the natriuretic response to diuretic therapy in heart failure with reduced ejection fraction and volume overload. Acta Cardiol. 2015, 70, 265-273. [CrossRef]

29. Moyer, J.H.; Ford, R.V. Laboratory and clinical observations on ethoxzolamide (cardrase) as a diuretic agent. Am. J. Cardiol. 1958, 1, 497-504. [CrossRef]

30. Dharia, S.M.; Brown, L.K. Epidemiology of Sleep-Disordered Breathing and Heart Failure: What Drives What. Curr. Heart Fail. Rep. 2017, 14, 351-364. [CrossRef]

31. Aurora, R.N.; Chowdhuri, S.; Ramar, K.; Bista, S.R.; Casey, K.R.; Lamm, C.I.; Kristo, D.A.; Mallea, J.M.; Rowley, J.A.; Zak, R.S.; et al. The treatment of central sleep apnea syndromes in adults: Practice parameters with an evidence-based literature review and meta-analyses. Sleep 2012, 35, 17-40. [CrossRef]

32. Verbraecken, J.; Willemen, M.; De Cock, W.; Coen, E.; Van de Heyning, P.; De Backer, W. Central sleep apnea after interrupting longterm acetazolamide therapy. Respir. Physiol. 1998, 112, 59-70. [CrossRef]

33. Massumi, R.A.; Evans, J.M. Studies on the continuous use of a carbonic anhydrase inhibitor (diamox) in ambulatory patients. Am. Heart J. 1955, 49, 626-632. [CrossRef]

34. Kataoka, H. Treatment of hypochloremia with acetazolamide in an advanced heart failure patient and importance of monitoring urinary electrolytes. J. Cardiol. Cases 2018, 17, 80-84. [CrossRef] [PubMed]

35. Leon Jimenez, D.; Gomez Huelgas, R.; Fernandez Romero, A.J.; Lopez Chozas, J.M.; Perez de Isla, L.; Miramontes Gonzalez, J.P. Diuretic treatment of the patient with diabetes and heart failure. Role of SGLT2 inhibitors and similarities with carbonic anhydrase inhibitors. Rev. Clin. Esp. 2018. [CrossRef]

36. Mullens, W.; Verbrugge, F.H.; Nijst, P.; Martens, P.; Tartaglia, K.; Theunissen, E.; Bruckers, L.; Droogne, W.; Troisfontaines, P.; Damman, K.; et al. Rationale and design of the ADVOR (Acetazolamide in Decompensated Heart Failure with Volume Overload) trial. Eur. J. Heart Fail. 2018, 20, 1591-1600. [CrossRef] [PubMed]

37. Nunez, J.; Heredia, R.; Paya, A.; Sanchis, I.; Del Prado, S.; Minana, G.; Santas, E.; de la Espriella, R.; Núñez, E.; Sanchis, J.; et al. Use of acetazolamide in the treatment of patients with refractory congestive heart failure. Cardiovasc. Ther. 2018, 36, e12465. [CrossRef] [PubMed]

38. Terziyski, K.; Draganova, A. Central Sleep Apnea with Cheyne-Stokes Breathing in Heart Failure-From Research to Clinical Practice and Beyond. Adv. Exp. Med. Biol. 2018, 1067, 327-351. [PubMed]

39. Verbrugge, F.H. Editor's Choice-Diuretic resistance in acute heart failure. Eur. Heart J. Acute Cardiovasc. Care 2018, 7, 379-389. [CrossRef] [PubMed]

40. Verbrugge, F.H.; Martens, P.; Ameloot, K.; Haemels, V.; Penders, J.; Dupont, M.; Tang, W.H.W.; Droogné, W.; Mullens, W. Spironolactone to increase natriuresis in congestive heart failure with cardiorenal syndrome. Acta Cardiol. 2018, 1-8. [CrossRef]

(C) 2019 by the authors. Licensee MDPI, Basel, Switzerland. This article is an open access article distributed under the terms and conditions of the Creative Commons Attribution (CC BY) license (http://creativecommons.org/licenses/by/4.0/). 